\title{
Research on the Extracurricular Sports Activities of Higher Vocational Students Based on the "National Games" Model
}

\author{
Jingrui Chen \\ Qingdao Technical College, Qingdao 266000, China. \\ 18953282595@126.com
}

Keywords: Higher Vocational Students National Games Extracurricular sports activities.

\begin{abstract}
The National Games are the highest and largest comprehensive sports meeting in China. It is an important way for the state to select sports talents. In this paper, we borrow the word and give it a new meaning. It means that all the teachers and students will participate in all kinds of sports activities in an all-round way, so as to achieve the purpose of activating campus sports atmosphere and cultivating good sports habits.
\end{abstract}

\section{Introduction}

In order to further promote the sports fitness activities carried out orderly, comprehensive implementation of the general office of the State Council on the relevant document to strengthen the school sports promoting students' physical and mental health of the Ministry of education and comprehensive development of opinions "higher school sports work basic standard" spirit, follow the "full participation, health and fitness" purposes, according to the characteristics of the short time in Higher Vocational students. Start a new innovation mode of extracurricular sports activities more and more vocational colleges, breaking the traditional campus sports activities around the spring semester of campus sports meeting, the fall semester carries out the sun long and new basketball single mode, mobilize the enthusiasm of students as the starting point to the maximum. In order to develop the students' physical exercise habits, the activities of each event are actively connected in series and combined scientifically. To promote the orderly development of physical fitness activities in schools and to improve the physical quality of higher vocational students.

\section{Extracurricular Sports Activities for Students}

\subsection{The Present Situation of Extracurricular Sports Activities for Students in Higher Vocational Colleges.}

The survey on the arrangement of students' after-school time in higher vocational colleges shows that the proportion of boys and girls in extracurricular sports activities is relatively low. The proportion of boys participating in extracurricular sports activities is $29 \%$, and girls only $12 \%$. The proportion of girls participating in extracurricular sports activities is obviously lower than that of boys, which reflects that the initiative of girls to participate in extracurricular sports activities is lower than that of boys. The frequency of extracurricular sports activities in higher vocational colleges is unstable and random, and the time of exercise is obviously insufficient. The content of the activities is diversified, the selection of activities is realistic, the physical quality is emphasized and the value orientation is taken into consideration. The selection of extracurricular sports participation forms, activities and places has obvious gender characteristics, and the motivation to participate in extracurricular sports activities is multi-level. 


\subsection{Factors Influencing Students' Participation in Extracurricular Sports Activities in Higher Vocational Colleges. \\ 2.2.1 The Influence of School Sports Facilities and Sports Equipment on Extracurricular Sports Activities.}

The main reasons that impede students' participation in extracurricular sports activities are the lack of sports facilities and sports equipment. Although some large scale high education parks have been built in different places in recent years, the area of new campus has multiplied by the replacement of urban land. The construction of sports facilities and sports equipment in school has also been well developed. But in recent years, higher vocational colleges generally expand enrollment, and the number of students is expanding rapidly, resulting in the contradiction between normal sports teaching and extracurricular sports activities for students, which demand for sports facilities and sports equipment. The necessary material conditions for students to participate in extracurricular sports activities are limited.

\subsubsection{The Influence of Leisure Time on Participating in Extracurricular Sports Activities.}

"No time" is an important factor that restricts students to participate in extracurricular sports activities. Although school hours and schedules have explicit rules for extracurricular activities, school culture curriculum arrangement often conflicts with extracurricular activities in actual operation. According to the survey, the students generally reflect that the afternoon culture course is too much arranged, and the rest time is in contradiction with the extracurricular sports activities.

\subsection{The Necessity of the Implementation of the National Games Model}

At present, the development of extracurricular sports activities in higher vocational colleges mainly relies on the school league committee or student management department, taking the sports associations as the carrier, and the departments as the center, and the extracurricular sports activities framework. Due to the different preferences of sports agencies and institutions, the sports events often have some limitations. The participation groups are often limited to their departments and lack overall consideration. The mode of the National Games provides new ideas and methods for the development of sports activities in higher vocational colleges.

\subsection{Construction of Extracurricular Sports Activities of Higher Vocational College Students under the Mode of the National Games}

The level of physical health of students directly affects the successful employment in the future. How to make use of the leisure time of students and teachers after class and make use of the time in school as far as possible, to ensure the effect of exercise, and to develop the habit of physical exercise. Students should learn one kind of sports that interested themselves. Through the reform of extracurricular physical education teaching mode, the system of extracurricular sports activities for students in Higher Vocational Colleges under the mode of the National Games is constructed so as to improve the health level of all the members.

\subsubsection{Setting Up All Staff Participation System.}

The smooth development of the mode of the National Games is to begin with the attention of the whole hospital and the participation of all members. The premise of full participation is that there must be a certain constraint mechanism, according to the requirements of the National Games. The hospital departments reasonable division, each of the participating departments like to participate in the games of each of the participating provinces, at the same time to set bonus points throughout the year sports fitness project (usually personal challenge sports in accordance with the 9, 7, 6, 5, 4, 3, 2, 1 points, group competition according to individual cumulative integral multiples). At the same time, it is stipulated that the organizers of a single sports event should be rewarded with a certain score every time, encouraging teachers or students to serve as referees, and give some bonus points. The reward points obtained by the department or individual will be recorded in the college related sports system, and the system automatically accumulates scores and ranks automatically.

\subsubsection{Improving the Level of Referee's Discretion.}

There are more regular events in the National Games, and a few sports teachers from school participate in the referee of the National Games. 
Not enough. The school also regularly send teachers to attend business school after learning and the referee for the two time for training results. This is a process for physical education teachers to improve their professional level and expand their knowledge. At the same time, it is also a valuable experience for students who participate in training, which is of great significance for their future career.

\subsubsection{Arrangement of Scientific Planning Activities.}

The annual activities of the National Games should not only reflect the overall content of the activities, but also make a reasonable classification. It is also necessary to consider factors such as season, sexual distinction of the students, major festivals of the college and so on.

Table 1. The frequency, time and time period of extracurricular sports activities for students in Higher Vocational Colleges

\begin{tabular}{|c|c|c|c|c|c|c|c|c|c|c|c|}
\hline & \multicolumn{2}{|c|}{$\begin{array}{c}\text { Frequency of } \\
\text { activity }\end{array}$} & & & \multicolumn{2}{|c|}{$\begin{array}{l}\text { Activity time } \\
\text { per day }\end{array}$} & & & \multicolumn{2}{|c|}{$\begin{array}{l}\text { Active time } \\
\text { period }\end{array}$} & \multirow[b]{2}{*}{ Weekends } \\
\hline & $\begin{array}{l}\text { More } \\
\text { than } \\
3\end{array}$ & $1-3$ & & Non-participation & 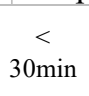 & $30-6$ & $\mathrm{n}>60 \mathrm{~min}$ & Morning & Afternoon & Evening & \\
\hline Boys & $\begin{array}{c}25 . \\
2\end{array}$ & 47.8 & 23.3 & 3.7 & 40.1 & 26.6 & 33.3 & 16.6 & 69.3 & 24.1 & 27.8 \\
\hline Girls & $\begin{array}{c}2 \\
15 . \\
1\end{array}$ & 43.9 & 36.3 & 4.7 & 64.7 & 28.4 & 6.9 & 15.2 & 59.8 & 25.0 & 16. 0 \\
\hline Total & $\begin{array}{c}20 . \\
3\end{array}$ & 45.9 & 29.6 & 4. 2 & 52. 1 & 27.5 & 20.4 & 15.9 & 64.7 & 24.5 & 22.8 \\
\hline
\end{tabular}

According to the improvement of the students, the whole games can be divided into six sections.

The first section: sports competition section. Through the development of competitive activities, we can fully arouse the enthusiasm of our classmates to participate in sports, and fully demonstrate the spirit of unity and cooperation, striving for success and positive spirit in sports activities, so that participants can experience the charm of sports.

The second section: physical fitness activity section. Through the development of fitness activities, students will be actively involved in the initiative to participate in sports activities. At the same time, we should further cultivate courage and confidence in challenging difficulties, strengthen collective cohesion and build a harmonious interpersonal relationship.

The third section: team activity section. Through team development and interesting sports programs, we will create a wide range of fitness platform for students to develop various forms of sports.

The fourth section: sports intelligence competition section: Through sports intelligence competition, expand students' thinking ability and team collaboration ability.

The fifth section: dance section. The establishment of College Aerobics and other activities, focusing on the growth of student girls. Promote the enthusiasm of students to participate in activities, cultivate students' sentiment, and activate the campus sports atmosphere. Through this activity, the participants are guaranteed to enjoy one or several kinds of aerobics dancing to help them develop their lifelong physical exercise habits.

The sixth section: Sports event service section. Participate in and innovate the management, referee and competition service of the student as the main body.

\subsection{The Meaning of Extracurricular Sports Activities of Higher Vocational College Students under the Mode of the National Games}

\subsubsection{Motivation of Students Participating in Extracurricular Sports Activities in Higher Vocational Colleges.}

Higher Vocational College Students' motivation to participate in extra-curricular sports activities can cause and maintain the internal psychological motivation of students to participate in physical training and physical training activities, play orientation, initiation and regulation, strengthen and maintain the function of physical exercise and learning behavior. The survey shows that $43 \%$ of boys believe that taking part in extracurricular sports activities is to enhance their physique, $45 \%$ of boys think they can enrich their after-school life, and $48 \%$ of boys think they can entertain. $54 \%$ of the female students believe that taking part in extracurricular sports activities is for body building and 
weight reduction. $36 \%$ of the girls think that they can enrich their after-school life, while 30 of the girls think they can adjust their body and mind. This shows that most of the students in higher vocational colleges have a clear understanding of the extracurricular sports activities, and the motivation is healthy and positive. At the same time, there are some bad factors. $32 \%$ of the girls and $14 \%$ of the boys participated in the sports activities to cope with the exams, and they were not well aware of the purpose of taking part in physical exercise. This requires that the physical education teachers can actively guide the students, make them form the correct motivation and develop the habit of good exercise.

\subsubsection{The Significance of Extracurricular Sports Activities.}

The extracurricular sports activities play a significant role of the school sports. It is complementary to the physical education and sports training, and the goal of the school sports is completed together. Students can use the free time to have extracurricular physical exercise. We should use various methods of body exercises, combine natural forces and health measures to carry out regular comprehensive physical exercise. Improve the students' physique and cultivate their exercise habits. The aim is to adjust the spirit and enrich the extracurricular life to promote the overall development of the students. Extracurricular sports activities are to take into account students' interests, hobbies, talents and specialties, and focus on improving the sport skills and the quality of extracurricular sports. It is also beneficial to enhance the students' physical fitness and complete the basic task of school physical education. The relationship between extracurricular sports activities and physical education is the supplement, continuation and enthusiasm of physical education. It is the spare time of the students and is not bound by the fixed mode. According to his own interests, hobbies, and sports skills, give full play to their specialty and personality.

The active physical exercises and the ability to develop sports, and show the means of movement. In this case, the national games model is used in extracurricular sports activities. With its rich content, various forms, the sports items that students are pleased to see, the flexible and sufficient time of activity, attracting the students to participate actively. Extracurricular sports activities are conducive to mobilizing students' enthusiasm for physical exercise, improving their athletic ability and level, and developing scientific, healthy and civilized life habits, which is conducive to improving teaching quality and cultivating students' interests and hobbies. It is an important part of school physical education to carry out all the policies and regulations of school sports. To carry out extracurricular activities in the National Games mode is to mobilize students' enthusiasm better and make students integrate into Extracurricular Sports in a more systematic and authoritative way.

\section{Suggestions on Extracurricular Sports Activities of Higher Vocational College Students Under the Mode of The National Games}

The extracurricular sports activities in higher vocational colleges should meet the students' interest requirements, and the requirements for the facilities of the field are not high, and the sports items like the students should be promoted actively. The organizational content of extracurricular sports activities should be rich and adaptable to a wide range. We should pay attention to the cultivation of students' sports consciousness and the habit of taking part in physical exercise for a long time.

Through the establishment of student extracurricular sports clubs, personal sports associations and sports interest groups, we should strengthen the organization and guidance of extracurricular sports activities in higher vocational colleges. The school planned small sports competition task is assigned to the organization. The sports department is guided by business and moderately supported by funds, so that students with different sports interests have the opportunity to participate in competitions and play their roles. To mobilize the enthusiasm of students to participate in extracurricular sports activities to the maximum extent. Lack of sports facilities in schools, poor students' sports awareness and the lack of effective organization and management of extracurricular sports activities are the main factors. Carrying out extracurricular sports activities in the mode of the National Games can appropriately reduce this phenomenon. Taking the National Games as a mode to enable students to 
participate in physical exercise organically, it is necessary to ensure the normal operation of extracurricular sports activities in higher vocational colleges.

\section{Summary}

The national games model is an effective attempt of extracurricular sports activities in higher vocational colleges. He divides all sports events in the year according to the sections. Both individuals and groups have the opportunity to participate in the events. From the organizational arrangement, it is more systematic and comprehensive, and the participants are rewarded with accumulative integral. We have really done the public participation and the national fitness. In the past few years, it has received good results, greatly enriched the extracurricular sports activities of students, and played a good role in promoting the physical fitness of vocational college students.

\section{References}

[1]. Cheng Jingrui, Research on the extracurricular sports activities of Higher Vocational Students Based on the "National Games" model[J] Journal of Qingdao Technical College

[2]. Peng Ming, Study on the present situation of college students participating in extracurricular physical exercise [J] Journal of Nanjing Sport Institute, 2005(3):39-40.

[3]. Dong Xiaohong, An analysis of the current situation of physical education and exercise of College Students[J], Journal of Beijing Sport University,2006,29(3):390-392.

[4]. Wu Qiulin, Investigation and Analysis on the present situation of extracurricular sports activities of college students in Jiangxi[J], Sports science and technology in China, 2002 (6) :42 44. 